\title{
SOCIAL WORK
}

\section{Parent-child interaction in families, who have children with disability}

\author{
Y. M. Shvalb, N. V. Butenko \\ Department of social work, Taras Shevchenko National University of Kyiv, Kyiv, Ukraine \\ Corresponding author. E-mail: shvalb2012@ukr.net; bootenkonadia@gmail.com \\ Paper received 30.08.19; Accepted for publication 14.09.19.
}

https://doi.org/10.31174/SEND-HS2019-205VII34-14

\begin{abstract}
The article is devoted to the research of parental-children relationships in families, who have children with disability. Basing on the results of the PARI questionnaire, the author analyzes peculiarities of attitude towards family role and family relationships. The discussion is mostly focused on how families structure their life and how it manifests in everyday communication. Also, the article describes the types of family interaction, which were divided using factor analysis. These types of interaction define how families behave in internal life and external communication.
\end{abstract}

Keywords: families with children with disability, parent-child relationships, family interaction, interfamily communication.

Introduction. In work with families, who have children with a disability, one of the important factors is the establishment of the peculiarities of parent-child relationships and determination the type of interaction within the family.

These parameters, along with the personal characteristics of the parents, the child's level of development and the level of adaptation of the family in society, are the key in the forming process of family representations about children disability. Such kind of representations also determines the behavior of the family in society and determines the successful providing social services to them.

The determination of characteristics of parent-child relationships is also useful for understanding the peculiarities of internal family interaction. And it also is useful for developing and managing the program of correction or support.

Reviewing research-related publications. In a study of families with a child with a disability, more attention pays for the definition of certain problems of these families. Maistruk \& Luchakivska (2010) indicate that families, who have children with disability face such problems as: deterioration of psychological health in family, the lack of information, imperfection of law system, particularly in the process of protecting the rights of children and their families, and also in service delivery process, the absence of convenient system of social services [5]. Jarskaja-Smirnova \& Naberushkina (2004) notice that the functioning of families, who have children with disability, can be considered not only by problems (as a result of a medical approach to disability) but also by limitations in social life (as a result of social approach) [3].

Giulio, Philipov, Jaschinski (2014) note that the birth of a child with disability effects on the quality of life of the family, gender roles of parents, economic resources and social status, activity and health features in the family [2, p. 2].

Levchenko \& Tkacheva (2009) define that in families, who have children with disability, there are changes on three levels of functioning: psychological, social and somatic. Changes on psychological level mean that parents and other members of the family, who include in the process of care of children with disability, struggle from interpersonal experiences (such as acceptance of the fact of disability, definition the further ways of development). Social changes mean the transformation of the network of family communication: it can be expanded or reduced, but it comes on the new level of functioning. Somatic level means that it can be bodily eruptions as a result of experience [4].

Also, there are investigations dedicated to the study of internal family characteristics. Zaitsev (1999) defines that families with children with disability, besides the general family functions, perform specific functions such as the function of habilitation and rehabilitation, the function of correction and compensating function. [9, p.26-27].

Boldina (2006) describes four types of families with children with disability. The first type has expanded the sphere of parental feelings and characterized by the hyperopic style of raising. They focus on children's needs and promote developing relationships of dependence. The second type is characterized by decreasing emotional support and communication between parents and children. Parents focus mostly on the rehabilitation of children but pay less attention to interaction. The third type has cooperation type of interaction. It means that parents together with children try to cope with problems and share the responsibility. The fourth type of families has a repressive style of family communication and focus on pessimistic view on the future [1, p. 73-74].

The establishment of the fact of disability influences both on parents and children. Zakharov (1995) notices that parents, who have disabled children may have such neurotic changes as emotional sensitivity, affectiveness, anxiety, conflict of personality, hypersociality [8, p. 34].

On the other hand, Polouhina (2008) describes that children with disability characterize by high dependence on family, lack of external social interaction skills, inappropriate behavioral reactions, they may have elements of autistic behavior in the family, inclined to the formation of neurotic features [6, p.144].

Despite all these studies, there are not enough researches about the peculiarities of parent-child relationships and the connection between internal and external family interaction.

Objective. The purpose of the article is to analyze the characteristics of parent-child relationships in families, 
who have children with disability and determine the basic types of family interaction.

Materials and methods. The investigation was conducted on 119 families, who have children with disability from 7 to 15 years old. $90.8 \%$ of respondent were women, $9.2 \%$ - men. Method that there were used in investigation: questionnaire, semantic differential scale, Parental Attitude Research Instrument (PARI; developed by Schaefer E. \& Bell R., adapted by Neshheret T.V.), Family Adaptation and Cohesion Scales (FACES-3; developed by Olson D. H., adapted by. Jejdemiller Je.G), Rotter's Locus Control Scale (adapted by Bazhin E.F, Golynkina S.A., Jetkind A. M.). The article is focused mostly on the results from the Parental Attitude Research Instrument (PARI).

The PARI aims are to determine the peculiarities of parents' attitudes towards different aspects of family life and relationships with the children [7, p. 436-451]. The questionnaire consists of 23 scales, which are divided by types of attitude towards family role and the parent-child relationship.

Discussing results. Attitudes towards family role are described by 8 scales that relate mainly to the peculiarities of self-perception within intra-family relationships. During the experiment, it was determined that families who have children with disabilities mostly have such averaged values of these scales:

Table 1. The averaged values of the scales of attitude towards the family role

\begin{tabular}{|l|l|}
\hline Name of scale & $\begin{array}{l}\text { The averaged } \\
\text { values }\end{array}$ \\
\hline Seclusion of the mother & 13.28 \\
\hline Feeling of self-sacrifice of the mother & 13.59 \\
\hline Marital conflicts & 13.43 \\
\hline The authoritarianism of parents & 15.51 \\
\hline Dissatisfaction with the role of hostess & 12.26 \\
\hline Inconsiderateness of the husband & 12.56 \\
\hline Ascendance of the mother & 13.12 \\
\hline Mother dependence and non-autonomy & 14.07 \\
\hline
\end{tabular}

Although the obtained results indicate the average level of manifestation of each feature, it can be noticed an upward tendency on the scale "Authoritarianism of parents" (value 15.51). 38.88\% of respondents received high scores on this scale. It means that in families who have children with disability, parents are more powerful in the decision-making process, also they have more responsibility in solving problems. But such kind of their behavior leads to the fact that other members of the family, both young and old, became excluded from the family life, their views do not take into account and they become dependent from the parental decisions.

In general, the attitude towards family role can be described as not limiting by family affairs and child-rearing issues. According to the data, respondents do not show dominance or suppressing behavior in the interaction with the child. In interaction with husband, women do not feel his indifference and insensitivity to the issues of family life; they believe that the husband is sufficiently involved and interested.

Even though the female respondents do not note their dependence and non-autonomy as a mother, $22.22 \%$ of the respondents received high marks on this scale. High scores on this scale can be logical in the case when mothers are unemployed and receive all financial assistance from a husband or other member of the family. Mothers may also feel dependent if they have a strong connection with the child and structure their life basing on the needs and interests of the child, which they consider to be prior. At the same time, they can ignore their interests, the real interests of the child, focusing on what they consider to be necessary. When they are allowed to go about their own business, then they cannot find out how to organize their lives and need someone's help.

However, 9.5\% of respondents have a feeling of selfsacrifice, despite the averaged value of 13.59 on the scale "Feeling of self-sacrifice of the mother". It is necessary to pay attention to this feeling while working with parents, to prevent dissatisfaction and neurotics in the future.

$19.44 \%$ of the respondents indicate that they have a limited only by family matters, according to the results on the scale "Seclusion of the mother". It means that respondents could reduce the number of external social contacts, number of hobbies and passions on their own, and focused only on family life.

On the scale "Marital conflicts" only $7.4 \%$ of respondents received high scores. It indicates that the type of family interaction, which is established in families with children with disability, provides peacefulness and calm resolution of controversial issues. This may be because, in the families, who have children with the disease, parents try not to create stressful situations, avoiding confrontation.

In addition to this group of scales, it can be noticed that families do not have significant problems in their life. Disability became an integral part of their life, and all roles, functions, and duties are divided according to the needs of disability. Families structure their life in a way that helps them to reduce negative manifestations of disability as a limitation in social life. Such way of life organization may not match the criteria of "ideal" life, but it helps families.

Attitude towards the child is described by 15 scales, which are divided into three groups: excessive concentration on the child (described by 8 scales); optimal emotional contact (described by 4 scales); excessive emotional distance (described by 3 scales).

The results obtained from these groups are the following:

Table 2. The averaged values of the scales of attitude towards the parent-children relationship

\begin{tabular}{|l|l|l|}
\hline Name of scale & $\begin{array}{l}\text { The averaged } \\
\text { values }\end{array}$ \\
\hline \multirow{4}{*}{$\begin{array}{l}\text { Excessive con- } \\
\text { centration on the } \\
\text { child }\end{array}$} & $\begin{array}{l}\text { Excessive care, fostering } \\
\text { dependency }\end{array}$ & 12.54 \\
\cline { 2 - 3 } & Breaking the will & 13.72 \\
\cline { 2 - 3 } & Excluding outside influences & 12.56 \\
\cline { 2 - 3 } & Suppression of aggression & 13.16 \\
\cline { 2 - 3 } & Suppression of sex & 11.64 \\
\cline { 2 - 3 } & $\begin{array}{l}\text { Excessive interference in } \\
\text { child's life }\end{array}$ & 13.02 \\
\cline { 2 - 3 } & Acceleration of development & 12.29 \\
\hline \multirow{2}{*}{$\begin{array}{l}\text { Optimal emo- } \\
\text { tional contact }\end{array}$} & Encouraging verbalization & 15.47 \\
\cline { 2 - 3 } & Partnerships & 16.14 \\
\hline
\end{tabular}




\begin{tabular}{|l|l|l|}
\hline & Approval of activity & 14.49 \\
\cline { 2 - 3 } & $\begin{array}{l}\text { Equalitarianism in child } \\
\text { rearing }\end{array}$ & 15.20 \\
\hline \multirow{2}{*}{$\begin{array}{l}\text { Excessive emo- } \\
\text { tional distance }\end{array}$} & Irritability & 12.88 \\
\cline { 2 - 3 } & Strictness & 11.94 \\
\hline
\end{tabular}

Indicators that belong to the group "Excessive concentration on the child" are average, which means that there are no deviations in the interaction of parents and child. It is important to notice that in each group of attitude, indicators can manifest both in positive and negative way. Even the group that seems to be appropriate for adequate parent-children relationships can be consists of inappropriate behavioral patterns.

A value of 12.54 on the scale "Excessive care, fostering dependency" indicates that most parents do not overcare or neglect parenting; they try to raise the child as a separate family member, without creating a fusion of mother and child. At the same time it was observed that some mothers have constant physical contact with their children: hold them by the hand, hug or simply hold a hand on the child's shoulders, constantly adjust their hair or clothing, kiss, etc. Such behavior is more commonly observed in families raising children with musculoskeletal disorders. Moreover, according to the level of children development, they do not need outside help; they could walk by their own or do necessary tasks. However, mothers tried to keep them close all the time.

A value of 13.72 on the scale "Breaking the will" indicates that there are cases of confrontation between the child's and the parent's point of view. Only $12.03 \%$ of respondents have high scores on this indicator. According to the age of the children, it can be assumed that this has happened due to the particularities of the children's development when they try to become independent of parental care and behave as an adult. However, it can also be related to the peculiarities of the child's physical state, when certain diseases cause deviant behaviors and parents are forced to constantly monitor and suppress them.

Due to the score on the scale "Security creation, restriction of new experience", parents are trying to create the most comfortable and safe environment for the child. This can be demonstrated in limitation external contacts, avoiding family conflicts, excessive anxiety about present and future. Such type of behavior should also be considered while creating a program for parents, because creating such "isolated" environment for children blocks access to other behavioral patterns.

The values 13.16 and 11.64 received on the scales "Suppression of aggression" and "Suppression of sex" indicate that in the interviewed families, children do not demonstrate contradiction behavior or excessive aggression when they become angry, and also do not exhibit deviant sexual behavior.

Results on the scale "Excluding outside influences" indicates that families do not close from surrounding; external family contacts, and collaborate with various organizations and agencies. Family interaction is defined by family communication, which can be internal and external. Internal communication - is a closed space; only family members take part in it. External communication includes all forms of interaction with society. As usual, the quality of external communication depends on the quality of internal communication.

$37.03 \%$ of respondents have high results on the scale "Encouraging verbalization", which means that families have a well-established internal communication process when all family members are involved in the interaction and decision-making process, take part in a discussion of all important questions and encouraged to express their thoughts and feelings.

It is also worth to note that in general the results of the group "Excessive concentration in the child" show that in families, who have children with a disability, respect their personality and do not interfere with their personal interests.

In the group "Optimal emotional contact with the child" all indicators tend to be increased. A value of 16.14 on the scale "Partnerships" indicates that parents act with their children as full partners in a relationship, that is, have equal duties. On the one hand, it is very good because no one is taking all responsibility, but on the other hand, it must be monitored to ensure that the children are not given too much freedom and responsibility (especially if they have not yet reached the appropriate level of development).

Results on the scale "Equalitarianism in childrenrearing" tend to be high, which show that parents have equal relationships with the child that they can delegate some of their rights and responsibilities to them. Withal parents need to maintain equal communication with the children (respect their interests and personality, consider the needs), but hold a parental position to them.

The increasing tendency is observed on the scale "Approval of activity" (value 14.49), which indicates that parents are trying to develop children. At the same time, the result on the scale "Acceleration of development" indicates that parents accept their children physical state, due to their peculiarities of perception of the child. $72.4 \%$ of the respondents received average scores on this scale, which, one the one hand, indicates that they do not try to hasten their development of children, and on the other hand they do not artificially inhibit it. As usual parents are interested in different ways and method that help to improve children's physical, cognitive and emotional state. Most of them try to take part in different trainings, lections, classes that provide information about children's development. They also prefer to participate together with children in different activities, learn something new rather than just watch.

In the group "Excessive emotional distance" the indicators tend to decrease compared to the average. According to the results on the scale "Irritability", parents may show some intolerance to the behavior of their children. This can be manifested when children do not listen and execute requests, feast, refuse to do something. But parental annoyance can also occur when children cannot do something or do not try their best. For example, cannot stand or sit still for a long time or distract while eating. Also, this indicator shows high results when parents are simply tired and in need to rest, so they may react a little sharply to their children's behavior.

A value of 11.94 on the "Strictness" scale means that parents do not make high demands on their children and do not expect extraordinary things from them. This may 
be related to the characteristics of the sample, as some respondents raise children who cannot reach such level of development to adequately evaluate their actions and make their own decisions.

A value of 11.66 for the "Avoidance of communication" shows that respondents are not afraid to interact with their children, they still try to accompany and support them throughout raising. Avoidance of communication occurs in cases when parents cannot accept the children's personality or their physical state. They refuse to confess that their children are different from others, and they try their best in life.

Analyzing the received results, it can be concluded that parents have stable relationships with their children and family in general. Comparing results from the attitude towards parental-child relationship, it can be concluded that group "Optimal emotional contact with the child" received $29.5 \%$ of high score answers, group "Excessive emotional distance" got $9 \%$ of high score, and in group "Excessive concentration on the child" only $5 \%$ of respondents got high scores.

At the next step of the investigation, there was decided to research how family interaction divided into groups, depending on features from scales. To determine the type of family interaction there was conducted a factor analysis. As a result of the analysis, there were defined three factors; each of them describes the type of family interaction that exists in families with children with disability.

The first factor is called "Sacrificial interaction" and it describes $24 \%$ of the variance. This factor includes: excessive interference in child's life (contribution to the factor -0.825$)$, seclusion of the mother (0.765), acceleration of development (0.703), feeling of self-sacrifice of the mother (0.692), excluding outside influences (0.654), breaking the will $(0.636)$, approval of activity $(0,634)$, authoritarianism of parents $(0,614)$, irritability $(0,581)$, suppression of aggression $(0,553)$, excessive care, fostering dependency $(0,537)$, ascendance of the mother $(0,490)$.

This type of interaction is characterized by preferring the children interests over other family issues, bringing them to the forefront and ordering the family's life according to children needs. Parents may feel guilt for children's health problems, and trying to fix it they become to ignore real-life issues, focusing only on disability. During the research, it was found that such type of interaction is connected to the locus control. It means that parents are inclined to feel responsible for all situations. Parents want so much for the best of their child that they isolate her from the environment on the one hand, and on the other, begin to tell her what they think is best for her. At the same time, parents may feel dissatisfied with themselves or their current situation because they do not always succeed. All problems and needs are developed from the disability, and all family resources spent on disability.

Disability becomes a main source of needs and interests and the whole life structure according to it. Child as an "owner" of disability defines the direction in family life. In external communication, such behavior is also demonstrated by using disability as a shield.

On the other hand in such type of families parents try to do their best for their children, so they communicate with doctors, teachers, social workers, psychologists, trying to find the newest and the most effective methods of rehabilitation.

The second factor is called "Dissatisfied with life" and describes $17 \%$ of the variance. It includes: dissatisfaction with the role of hostess $(0.841)$, strictness $(0.789)$, marital conflicts (0.734), security creation, restriction of new experience (0.637), mother dependence and nonautonomy (0.592), inconsiderateness of the husband (0.567), avoidance of communication (0.535), encouraging verbalization $(0.380)$. The factor is characterized by the dissatisfaction of all family members with the current situation, but also the unwillingness to change anything, creating the illusion of a "normal" life. Family members nominally perform their functions, but have no emotional contact and avoid a trusting relationship.

In external interaction, such families, as usual, are dissatisfied with services, which are provided to them. They may conflict with doctors or social workers, because, as they think, they do not pay enough attention to their problems or provided services with low quality. At the same time, such families visit all the events that are provided. Families do not want to discuss their life, thinking that all problems are the result of mostly external influences.

In behavior of such families there is mismatch between their assessment of services that are provided to them and attendance of all activities. As usual families are dissatisfied with quality of services but continue to consume them. It is also can be a phenomenon of "learned helplessness" when families can solve problems by their own but do not want to. They wait for external help, and when received it devalue it.

The third factor is called "Partnership interaction" and it describes $10 \%$ of the variance. It includes partnerships (0.774), equalitarianism in children rearing (0.594), and suppression of sex (0.359). This factor also includes encouraging verbalization (0.377), but it is also included in the second factor. This type is characterized by equal parent-child relationships when everyone contributes to establishing family relationships. Each family member has an opportunity to take part in a discussion of important issues and family listen to every opinion. At the same time, the children may be given too many rights that do not correlate with his or her age and level of development, which can lead to negative behavioral manifestations.

In such families members try together to cope with problems, they like to spend time together. In interaction, they mostly orient on external influences and resources. During the work with children, parents do not afraid to take part in the activities, to learn something new.

As a result of the analysis, it can be noticed that respondents have such types of interaction that seems to be ineffective because they are focused mostly on limitations and problems caused by disability. But each of the mentioned types is the result of the successful adaptation in society, which provides the successful functioning of the family. Every type gives something positive to every member of family, that is why they proceed such interaction.

Conclusion. In families with children with disability, relationships are mostly based on peculiarities of disability. Families percept disability as a necessary and integral 
part of life, and they do not know how to structure their lives in another way.

That is why, according to the results of Parental Attitude Research Instrument, in families, who have children with disabilities, mostly established optimal emotional contact with the children. It also can point that parents understand and accept the fact of disability, and also managed to adapt their family lives due to this fact.

Withal it important to notice that mothers, who have children with disability can feel loneliness, dependence on family. It can be connected to the fact that there is a high percentage of the mother who pays too much attention to their children.
Analyzing the type of family interaction, it was defined that there are three main types of interaction in families. Most of the families have sacrificed the type of interaction, which means that they sacrifice some of their interests and need to decrease the negative consequences of disability.

Received results are the basis or the further development of the socio-psychological program for work with parents. The aim of the program is decreasing negative effects of the disability, correction of behavioral patterns and contributing to more adaptation in society.

\section{REFERENCES}

1. Boldina, M. A. Problems of families, who have children with disability // Psihologo-pedagogicheskij zhurnal «Gaudeamus», 2006. Issue №2 (10), p. 71-77.

2. Giulio, P. D., Philipov, D., and Jaschinski, I. (2014). Families with disabled children in different European countries. Families and Societies. Working paper series. Avaliable at: http://www.familiesandsocieties.eu/wpcontent/uploads/2014/12/WP23GiulioEtAl.pdf

3. Jarskaja-Smirnova, E. R., Naberushkina, E. K. (2004). Social work with disabled people. Study guide. Sankt-Peterburg: Izd-vo «Piter», 2004, 316 p.

4. Levchenko, I.Iu. \& Tkacheva, V.V. Psychological assistance to family raising a child with developmental disabilities: Methodological manual. Moscow: Prosveshchenie, 2009. 239 p.

5. Maistruk, N.O. \& Luchakivska, A.R. (2010). Problems of families raising children with disabilities in modern Ukraine

in the context of social work]. Visnyk NTUU «KPI». Politologhija. Sociologhija. Prav/ 2010. Issue 3.

6. Polouhina, E. A. Family climat features in families with disabled children. Vestn. S.-Peterb. un-ta, 2008. Issue 3. P. 143$148 . \quad-\quad$ Avialable at: https://cyberleninka.ru/article/n/osobennosti-semeynogomikroklimata-v-semyah-s-detmi-invalidami.

7. Rajgorodskij, D. Ja. Practical psychodiagnosis. Methods and tests. Study guide. Samara: Izdatel'skij Dom «BAHRAH-M», $2001.672 \mathrm{p}$.

8. Zaharov, A. I. What do you need to know before the child's birth? SPb.: Gippokrat, 1995. 128 p.

9. Zajcev, D. V. Basis of correctional pedagogy. Saratov: Pedagogicheskij institut Saratovskogo gosudarstvennogo universiteta im. N.G. Chernyshevskogo, 1999. 110 p. 